\title{
How firms undertake organizational changes to shift to more-exploratory strategies:
}

\section{A process perspective}

\author{
Jane Bjørn Vedel* \\ Copenhagen Business School \\ Department of Organization \\ Kilen, Kilevej 14A \\ DK-2000 Frederiksberg \\ Denmark \\ Tel. $(+45) 53834078$ \\ E-mail: jbv.ioa@cbs.dk \\ Olga Kokshagina \\ RMIT University \\ Graduate School of Business and Law \\ 124 La Trobe Street, Melbourne VIC 3000 \\ Australia \\ Tel. $(+61) 412855051$ \\ E-mail: olga.kokshagina@,rmit.edu.au \\ Mines ParisTech PSL Research University \\ Centre for Management Science \\ 60 Boulevard Saint-Michel, Paris, 75006 \\ France \\ *Corresponding author
}

\begin{abstract}
Firms' organization of exploratory research has interested scholars of both research policy and organizational theory, yet we still know too little about how firms undertake organizational changes to shift to more-exploratory strategies. Adopting a process perspective, we explore this question through a longitudinal, comparative case study of a Danish pharmaceutical firm and a FrenchItalian semiconductor firm. We demonstrate how firms adjust their organizational structures to increase exploration, a process of constantly addressing countervailing organizational and interorganizational demands by deploying, combining, and changing balancing mechanisms at the organizational and managerial levels. Moreover, our findings show that firms' different organizational structures affect their adaptations to exploratory outcomes. These findings advance theory because they illuminate the dynamic interplay between firms' adjustments of organizational
\end{abstract}


structures and their movements toward more exploration. We use a recursive process model to theorize our findings.

Keywords: Balancing mechanisms, exploration-exploitation, organizational adaptation, organizational structures, process perspective. 


\section{Introduction}

Research-based firms depend on exploration to innovate and perform economically (Laursen and Salter, 2004; 2006). Yet, exploration involves operating in ambiguous and unpredictable environments (Eisenhardt et al., 2010) that are "different, harder, and more precarious than ... predictable environments" (Davis et al., 2009, p. 443) and entail "maneuvering in poor visibility" (Dattée et al., 2018). These conditions pressure firms to develop strategies and organization for exploration. Yet, technological innovation, global competition, and established firms' tendency to drift toward efficiency over time (Eisenhardt et al., 2010) constantly unsettle such strategies (Eisenhardt et al., 2010; Schreyögg and Sydow, 2010) and challenge firms' development of exploratory activities.

While previous research has explored firms' organization of external exploratory collaborations (Cassiman et al., 2010; Estrada et al., 2016), scholars have paid less attention to how firms enact internal organizational shifts to more-exploratory strategies. Yet, this latter topic requires investigation given that firms need to explore in order to succeed and given the challenges of successful exploration (Hoang and Rothaermel, 2016; Krishnan et al., 2016). In addition, the current global crises have increasingly required firms to adapt to changing environments and new conditions for exploration, which makes this topic particularly timely. Therefore, we explore how firms undertake organizational changes to adopt more-exploratory strategies. Focusing on firms' internal change processes is both important for extending our theoretical understanding of firms' exploratory strategies and directly addresses how firms can better transition to these strategies. In our context, "more-exploratory" signifies strategies involving a higher degree of exploration.

Research policy studies have focused mainly on firms' organization of research at the interorganizational level and have usually adopted a covariance model (Bishop et al., 2011; Cassiman et al., 2010; Järvi et al., 2018; Kobarg et al., 2019; Tzabbar et al., 2013). In contrast, theories of organizational structures, exploration-exploitation, balancing mechanisms, and organizational adaptation have taken a more dynamic, process-oriented approach and focused on 
both the interorganizational and organizational levels (Davis et al., 2009; Eisenhardt et al., 2010; Lavie et al., 2010; Schreyögg and Sydow, 2010). Davis et al. (2009) studied firms' development of optimal structures in unpredictable external environments, suggesting that established organizations must carefully manage both the amount and content of structure they develop. Exploring the environmental, organizational, and managerial antecedents of exploration and exploitation, Lavie et al. (2010) showed how firms use either separation or ambidexterity to reduce tensions resulting from these activities. Promoting a processual balancing perspective, Schreyögg and Sydow (2010) suggested that firms must constantly balance countervailing processes within their organizations and subunits. Eisenhardt et al. (2010) characterized the managerial actions by which firms balance efficiency and flexibility.

While these contributions have suggested the need for empirical, process-oriented studies of firms' transitions toward exploration, they have developed primarily conceptual insights. We therefore adopt a process perspective to empirically study how firms undertake organizational changes to shift to more-exploratory strategies.

To investigate our question, we focus on organizational structures because we assume that "structure lies at the heart of managing the tension between efficiency and flexibility" (Eisenhardt et al., 2010, p. 1265). Following organizational theory, we define organizational structures simply as "constraint on action" (Davis et al., 2009, p. 415; Eisenhardt et al., 2010, p. 1265). This simple definition allows us to consider multiple attributes of organizational structures, including rules, routines, hierarchy, use of authority, span of control, and role clarity; it also allows us to explore how firms adjust organizational structures over time by shifting from more to less structure (and vice versa) and by emphasizing certain attributes.

We conducted an inductive, comparative case study of a Danish pharmaceutical firm, Lundbeck, and a French-Italian semiconductor firm, STMicroelectronics (hereafter ST), both of which undertook organizational shifts to more-exploratory strategies. We studied each case longitudinally and compared how the firms developed and adjusted internal organizational 
structures for exploration. First, our multi-level analysis resulted in new theoretical insights regarding the dynamic interplay between the firms' structural adjustments and their shifts toward more-exploratory research. With these insights, we contribute to research policy studies on how firms organize exploratory research, and we answer the calls for organizational studies testing the “workability and practicality” of a processual balancing perspective (Schreyögg and Sydow, 2010, p. 1259).

Second, we demonstrate how firms deploy, combine, and change balancing mechanisms over time. With this finding, we advance organizational theory on exploration and exploitation, which has previously demonstrated mainly "pure modes of balancing" (Lavie et al., 2010, p. 145). Finally, we show how firms' choice of organizational structures affects their adaptations to exploratory outcomes. Consequently, we contribute to debates on structure, performance, and adaptation, which thus far have not focused on the process implications of adopting different structures (Davis et al., 2009).

In the following sections, we review the literature on firms' organizing of exploratory research and describe our conceptual framework. We then present our methods and findings and conclude by outlining our main contributions.

\section{Literature review and conceptual framework}

\subsection{Literature review}

Firms' organization of exploratory research has interested scholars of research policy and of organizational theory, but these disciplines have developed different approaches to the phenomenon.

\subsubsection{Interorganizational policy studies on how firms organize exploration}

Research policy studies have mainly conducted interorganizational analysis to investigate firms' organization of external collaborations. Adopting a covariance model, one group of studies has examined the relationship between knowledge attributes and organizational forms. Cassiman et al. (2010) found that firms seeking to develop novel or basic knowledge are likely to cooperate with 
universities, whereas firms seeking knowledge of strategic importance are likely to contract. Järvi et al. (2018) found that ecosystems seeking new knowledge domains are likely to organize in prefigurative organizational forms, whereas ecosystems designed to search within domains are likely to take partial forms (see also Bishop et al., 2011; Kobarg et al., 2019; Tzabbar et al., 2013). Although important, these studies have not considered the interplay between knowledge forms; rather, they explored the organizational implications of these forms separately.

Also at the interorganizational level, other studies have emphasized the interplay between exploration and exploitation. Gilsing and Nooteboom (2006) investigated the basic logic of change and innovation, explaining how exploration and exploitation dialectically build on each other in a “cycle of discovery" (p. 3). Emphasizing performance, Yamakawa et al. (2011) suggested that the benefits of an exploration-versus-exploitation type of alliance portfolio depend on how this orientation fits the firm's internal organizational characteristics, strategic orientation, and the industry environment (p. 287) (see also Cui et al., 2019). Focusing mainly on the external context, these studies have demonstrated the need for an organizational perspective.

Recent exceptions have taken this perspective, indicating scholars' evolving interest in the organizational context. Investigating how firms adapt their interorganizational relationships to changing environmental conditions, de Leeuw et al. (2019) found that firms adjust their portfolio diversity. Koryak et al. (2018) and Revilla and Rodríguez-Prado (2018) studied the tensions arising from exploration and exploitation and demonstrated firms' ambidextrous solutions to address these tensions (see also Crescenzi and Gagliardi, 2018). None of these studies has focused on the internal organizational changes that firms undertake to shift to more exploration.

\subsubsection{Organizational and interorganizational theory on firms' exploration}

In contrast, theory on structures, alliances, and adaptation has developed both organizational and interorganizational perspectives of firms' countervailing processes. These studies have emphasized firms' internal challenges in dynamic environments and how firms respond through 
organizational structures and balancing mechanisms (Davis et al., 2009; Eisenhardt et al., 2010; Lavie et al., 2010; Schreyögg and Sydow, 2010).

One group of studies has investigated the impact of organizational structures on learning, reorganization, and decision-making in the context of change (Bremner and Eisenhardt, 2019; Bresman and Zellmer-Bruhn, 2013; Clement and Puranam, 2018; Raveendran, 2020; Zhang et al., 2019). Of particular relevance, Davis et al. (2009) focused on how organizational structures influence efficiency and flexibility and whether it is better to err on the side of too much rather than too little structure. Defining organizational structures broadly as "constraint on action" (p. 415), the authors argued that entities are more structured when they shape more activities and thus constrain more action, and less structured when they allow more flexibility in organizational members' behavior. However, managing is harder in uncertain than in predictable environments (Davis et al., 2009, p. 443); thus, established organizations must constantly decrease structure but also carefully manage its amount, thereby enabling them to capture opportunities and recover from mistakes. This process indicates the dynamic role of organizational structures, but the above-noted studies have used primarily simulation methods, assuming "stylized environmental attributes" that call for "samples of real organizations and realistic environmental conditions" (Lavie et al., 2010, p. 119).

A second group of studies has explored the inherent contradictions between exploration and exploitation (March, 1991) and the associated tensions that firms must manage. Focusing on alliances (Das and Teng, 2002; Hannah and Eisenhardt, 2018; Wassmer, 2010), these studies have investigated how firms benefit from balancing exploration and exploitation (Lavie et al., 2011; Lavie and Rosenkopf, 2006; Stettner and Lavie, 2014). Acknowledging the difficulties of reconciling these elements (Posen and Levinthal, 2012), they have shown how firms address tensions by combining control mechanisms (Fernandez and Chiambaretto, 2016) and adapting their exploration levels to those of their partners (Duysters et al., 2018). Of particular relevance, Lavie et al. (2010) developed an extensive framework of exploration and exploitation, mapping their environmental, organizational, and managerial antecedents. Considering exploration-exploitation as 
a continuum, they identified four main modes of balancing, involving organizational, temporal, or domain separation, or contextual ambidexterity (described in detail below). While important, these studies have not developed a processual perspective of balancing, nor have they explored "how organizations combine several balancing modes when seeking to resolve the inherent trade-offs imposed by exploration and exploitation" (Lavie et al., 2010, p. 145).

Adopting a processual balancing view, a third group of studies has explored how organizations balance countervailing demands for efficiency and flexibility (Eisenhardt et al., 2010; Farjoun, 2010; Schreyögg and Sydow, 2010; Staber and Sydow, 2002). Arguing that change requirements are the most pressing challenge for organizational strategy and design, Schreyögg and Sydow (2010) claim that scholars' focus on enabling fluidity and change underestimates the importance of organizational identity and boundaries (p. 1253). "Conceiving of contemporary organizations in terms of dualistic, dialectic, or paradoxical processes" (p. 1256), the authors proposed that scholars focus not on specialization and the resulting tradeoffs but, rather, on how organizations manage contradictions by simultaneously balancing paradoxical tensions (p. 12571258). Consequently, organizations and their subunits must continually balance countervailing demands by monitoring stabilization mechanisms, identifying maladaptations early, and gaining flexibility through critical reflection (p. 1258).

Premised on this balancing perspective, the work of Eisenhardt et al. (2010) explored the managerial actions by which organizations balance efficiency and flexibility (p. 1265). Arguing that the links among organization, strategy, dynamic capabilities, and performance depend on how managers address the efficiency-flexibility tension (p. 1263), the authors claimed that organizations must be flexible to adjust to unexpected situations and efficient to gain acceptance, direction, and avoid mistakes. These important studies have developed mainly theoretical concepts and have called for research that empirically tests their "workability and practicality" (Schreyögg and Sydow, 2010, p. 1259). See Table A.1. 
Despite explicit calls for a process perspective (Azagra-Caro et al., 2017; Bahemia et al., 2018; Eisenhardt et al., 2010; Janssen et al., 2015; Järvi et al., 2018; Lavie et al., 2010; Schreyögg and Sydow, 2010), previous research has not adopted this perspective to empirically explore how firms shift to more-exploratory strategies. Consequently, scholars have also under-emphasized the organizational context for firms'shifts (Langley et al., 2013, p. 5). Moreover, as noted above, scholars have explored the role of organizational structures primarily through simulation studies (Davis et al., 2009) or as one among several dimensions of analytical importance (Eisenhardt et al., 2010, focus on structure, environment, and cognition, and Lavie et al., 2010, focus on environment, organization, and senior management). Finally, scholars have considered balancing primarily as an ongoing rather than a punctuated process (Eisenhardt et al., 2010), which has de-emphasized the landmark events that call for new balancing actions. Therefore, we adopt a process perspective to investigate how firms undertake organizational changes to adopt more-exploratory strategies.

\subsection{Conceptual framework}

We take an "integrative" approach to studying organizational movement toward exploration (Faems et al., 2008) by combining prior research on balancing mechanisms at the organizational (Lavie et al., 2010) and managerial levels (Eisenhardt et al., 2010) and by adding a context-specific mechanism for firms' balancing vis-à-vis emergent knowledge domains at different stages of maturation (Järvi et al., 2018). Our conceptual framework is multidimensional. First, it includes the countervailing organizational and interorganizational demands that firms address through their balancing mechanisms. Countervailing organizational demands arise when firms need to simultaneously ensure organizational efficiency and fluidity. Countervailing interorganizational demands emerge from firms' external operations involving environments with different dynamisms, external partners with different strategies, and knowledge domains with different degrees of maturation.

Second, our conceptual framework distinguishes organizational and managerial balancing mechanisms. The former are organizational actions to reduce tension from exploration and 
exploitation. These mechanisms work by either separating exploration or exploitation or addressing both simultaneously. The latter are the actions that managers deploy to balance tension arising from efficiency and flexibility; these actions often entail sophisticated solutions to safeguard organizational flexibility while addressing multiple external environments simultaneously. See Table 1.

Insert Table 1 here.

\subsubsection{Challenges and countervailing demands}

At the organizational level, firms operating in dynamic environments must reconcile the conflicting activities of exploration and exploitation. Tensions result from tradeoffs related to resource allocation constraints, short- versus long-term horizons, present versus future orientations, and stability versus adaptability (Lavie et al., 2010, p. 115-118). Established firms' efficiency drift makes it difficult to reconcile these activities, which makes protecting flexibility an ongoing concern (Eisenhardt et al., 2010, p. 1265-1267). At the interorganizational level, research-based firms simultaneously engage emerging knowledge domains at different maturational stages (Järvi et al., 2018), generating various demands. Moreover, organizations face environments with unique dynamics, such as ambiguity, which involves lack of clarity, unpredictability, and no clear underlying patterns leading to opportunities (Eisenhardt et al., 2010, p. 1267).

\subsubsection{Organizational balancing mechanisms}

At the organizational level, firms employ separation or ambidexterity to reconcile tensions from exploration and exploitation. Organizational separation entails separating units for exploration and exploitation; temporal separation involves sequential shifts over time from exploration to exploitation and vice versa; domain separation requires simultaneously exploring in one domain and exploiting in another; and contextual ambidexterity assumes no separation (Lavie et al., 2010). At the interorganizational level, firms can orchestrate knowledge domains in different maturational 
stages by combining diverse organizational forms. Firms use prefigurative forms to organize activities for seeking new knowledge domains, entailing affiliation-based participation, selfresourced inputs, and informal coordination (Järvi et al., 2018). Firms use partial forms to organize activities for seeking within knowledge domains, requiring formal membership and coordination (Järvi et al., 2018). To balance these activities, firms combine these forms within and across collaborations.

\subsubsection{Managerial balancing mechanisms ${ }^{1}$}

At the organizational level, managers address efficiency drift by unbalancing to favor flexibility (Eisenhardt et al., 2010). Managers unbalance by using heuristics-based, simple-rules strategic processes, including providing shortcuts to problem solving (p. 1266); simplification cycling, in which managers use their experiences to develop but also pare back structure (p. 1266); and flexibility-injecting structures, which involve temporary assignments, prototyping, and alliances rather than internal activities. At the interorganizational level, managers address several environments simultaneously by balancing for multiple environments.

Taking a process perspective, we do not assume that all firms experience the same challenges or address them through the same balancing mechanisms. We suggest that firms adjust organizational structures to respond to changes in context and use balancing mechanisms to address the changes. Therefore, our proposed framework can apply to contexts beyond our case studies.

\section{Methods}

\subsection{A process perspective}

To investigate our question, we adopted a process perspective (Cloutier and Langley, 2020; Langley, 1999; Langley et al., 2013). This perspective is useful for understanding "how and why things emerge, develop, grow, or terminate over time" (Langley et al., 2013, p. 1); therefore, it is useful for exploring how firms shift to more exploration. In a process perspective, the context "is not something that is held constant and outside the changes being analyzed but is itself continuously

\footnotetext{
${ }^{1}$ Since we focus on organizational and managerial mechanisms, we have left out cognitive mechanisms (Eisenhardt et al., 2010). Cognitive mechanisms are important but outside the scope of this paper.
} 
reconstituted within and by processes of interaction over time” (Langley et al., 2013, p. 5). By emphasizing the organizational context that research policy studies often neglect, we developed novel theoretical insights.

\subsection{An inductive, comparative case study of change in research-based firms}

We conducted an open inductive case study, which is suitable for investigating poorly understood phenomena (Glaser and Strauss, 1967) and for producing theoretical insights by examining data across sources (Eisenhardt, 1989; Yin, 1994). We took a longitudinal approach (Langley et al., 2013) to explore firms' movements to more-exploratory strategies. To generate robust, generalizable theoretical insights without compromising the data's richness, we conducted a comparative case study of two firms (Battilana and Dorado, 2010; Estrada et al., 2016; Rindova and Kotha, 2001).

We minimized extraneous variation (Eisenhardt, 1989, p. 537) by choosing established research-based firms that share certain characteristics. We selected a Danish pharmaceutical firm, Lundbeck, and a French-Italian semiconductor firm, ST, which are emblematic of researchintensive industries dealing with exploration-exploitation tradeoffs. We also ensured that our cases represented polar types whose processes of interest were transparently observable (Eisenhardt, 1989; Pettigrew, 1990). While both operate in R\&D-intensive industries and develop organizational structures for exploration, the firms differ in their life cycles, time to market, regulation, and the R\&D function itself. Both industries rely heavily on knowledge and innovation from higher education; yet, whereas the pharmaceutical industry has longer R\&D cycles involving drug discovery, pre-clinical trials, clinical trials, and safety and efficacy tests, the semiconductor industry reflects continuous growth in cyclical patterns with high volatility, requiring the R\&D function to adapt to an ever-changing environment.

\subsection{Research settings}

Lundbeck is a medium-sized Danish global pharmaceutical company specializing in the treatment of neuronal disorders such as Alzheimer's, Parkinson's, schizophrenia, depression, and 
anxiety. The company is fully integrated, with $\mathrm{R} \& \mathrm{D}$, production, and the marketing of drugs. ST is a leading French-Italian integrated device manufacturer, delivering key solutions for smart driving, smart industry, and smart homes and cities. By revenue, ST is Europe's largest semiconductor manufacturer.

External events led both firms to develop new exploratory strategies. At Lundbeck, the research management initiated new strategies to address a crisis in the pharmaceutical industry involving expiring patents, generic medicine, sluggish pipelines, and general pressure to focus on cures and prevention rather than on treating symptoms. At ST, the management responded to changing competition in the mobile phone market, in which established firms such as Nokia, Raspberry, and HTC were losing market share and new actors such as Apple had appeared. This change coincided with a general industry shift toward "More than Moore," referring to technologies and products not following the device scaling and cost reduction determined by Moore's Law.

\subsection{Data sources}

Our inductive approach led to a data set comprising 36 months of organizational ethnography for each firm. Ethnographic research is suitable for capturing the interplay of activity and meaning (Van Maanen, 2011) and for understanding how organizational phenomena evolve. We combined ethnographic observations with interviews and archival material. In both cases, we collected the data in three overlapping phases, focusing on the context of strategic change, the structures for exploration, and organizational adaptation of outcomes (see Table 2).

\section{Table 2 here.}

\subsubsection{Ethnographic observations}

The first author studied Lundbeck's research management from 2009 to 2011 (36 months). She observed all meetings relevant to the study, following a core team of executive managers and conducting daily observation and participation in more than 100 meetings, totaling more than 4000 
hours of observation. The meetings focused on strategy, specific collaborations, and ongoing research operations. Likewise, the second author studied ST's Advanced R\&D unit from 2010 to 2013 (36 months). She attended all relevant meetings and observed project reviews, everyday practices, and changes undertaken by the team, totaling more than 4000 hours of observation. Following standard ethnographic practice (Hammersley and Atkinson, 1998), both authors recorded their insights in field notes.

\subsubsection{Interviews}

Both authors conducted informal and formal interviews in all three phases. During the first phase, the first author conducted 24 interviews with the executive core team members, exploring strategies and the context for their changes. During the second phase, she conducted 14 interviews with key managers and researchers in the research division, focusing on specific exploratory collaborations. During the third phase, she conducted 12 interviews with the core team of executive managers, to understand the consolidation of exploratory strategies in the research division.

During the first phase, the second author conducted 28 interviews with managers and employees in the Advanced R\&D unit, external team members, Technology R\&D leaders, and business units, which characterized ST's R\&D organization. During the second phase, she conducted 27 interviews with team members and business unit managers, to understand ST's collaboration with scientific partners and Advanced R\&D's portfolio of industrial $\mathrm{PhD}$ projects and collaborative projects. During the third phase, she conducted 23 interviews, focusing on three cases of advanced technology development, to understand organizational structural changes over time. In both cases, interviews were transcribed when possible, or notes were taken.

\subsubsection{Archival material}

Given our privileged access, we collected extensive archival material, including meeting material (agendas, presentations, minutes), research collaboration documents (project descriptions, contracts), recorded correspondence (email exchanges), project review material (reports, 
presentations, evaluations), and strategy material (strategy documents, drafts, presentations). We used these proprietary documents to substantiate interview and observational findings.

\subsection{Data analysis}

We analyzed our data by using a "temporal bracketing strategy" (Langley, 1999, p. 703), whereby we grouped the data into phases to serve as comparable units of analysis. We analyzed the data separately and comparatively, accounting for differences and similarities between the firms' organization of exploratory research. We used open coding to break down the data into segments for comparison and novel reassembly (Strauss and Corbin, 1994).

We coded and analyzed our data in three rounds. First, we coded the data separately, focusing on the firms' exploratory strategies, organizational structures, and balancing mechanisms to address countervailing demands. This process resulted in two separate data structures that we used as our starting point to explore the significance of each case. We used an "insider-outsider" approach (Gioia et al., 2010) to challenge explanations and assumptions, grounding our findings in the firms' contexts, to maintain causal complexity (Ragin, 2014).

Second, we compared the cases to develop a higher-level data structure, to create generalizable categories. We identified overlaps in aggregate dimensions and differences in firstorder categories. Through multiple stages of case-specific, comparative and collaborative analysis, we developed a multi-level analysis of the interplay among countervailing demands, organizational structures, and balancing mechanisms. See Table A.3.

Finally, we clarified our contribution, discussing our emerging categories vis-à-vis organizational theory and research policy studies. We explored the relational dynamics between our constructs, resulting in a recursive process model (see Figure 1). We also discussed how our model provides new theoretical insights into the dynamic interplay between adjusting organizational structure and shifting toward exploration.

\section{Findings}


First, we present our findings by case and according to our three-phase periodization: 1) developing organizational structures for exploration, 2) conducting exploratory research with external partners, and 3) adapting the organization to exploratory outcomes. For each phase, we show how key events in the firms' organizational context changed the balance of countervailing organizational and interorganizational demands. We then demonstrate how the firms responded to these changes by adjusting their organizational structures and by deploying balancing mechanisms at both the organizational and managerial levels. Finally, we summarize our findings across the cases, comparing how the firms undertook organizational changes to increase exploration.

\subsection{Lundbeck}

\subsubsection{Phase 1: Developing organizational structures for exploration}

\subsubsection{The context}

To respond to a landmark change in market dynamics and an industrial emphasis on cures rather than symptom treatments, Lundbeck developed a new exploratory strategy. Like other pharmaceutical companies, Lundbeck faced the financial predicament of expiring patents of blockbuster drugs and a sluggish pipeline; in this context, Lundbeck's strategy for developing new products based primarily on modifying existing drugs was no longer sustainable. Lundbeck's new strategy aimed to increase research exploration and develop long-term, future-oriented innovation platforms.

Developed in 2005-2007 and gradually adjusted and implemented in 2008-2009, Lundbeck's exploratory strategy stemmed from guiding principles. It assumed that developing innovation platforms entailed understanding basic disease biology, identifying key biological mechanisms involved in neuronal disorders, and addressing these mechanisms in drug discovery. To remain flexible, Lundbeck's strategy entailed exploratory activities with external partners rather than building new capacities in house, based on "equal" scientific collaboration rather than their previous “cash-and-carry” model. The strategy unified Lundbeck's markets by identifying 
biological mechanisms involved in multiple neuronal disorders, thereby also revealing new indication areas.

\subsubsection{The countervailing organizational demands}

Lundbeck's shift to more exploration contrasted the firm's long history of emphasizing exploitation, reflected in its matrix structure of functions (neurobiology, pharmacology, and chemistry) and indication areas (depression and anxiety, schizophrenia and bipolar, Alzheimer's and Parkinson's diseases), and in its research processes, which the chemistry division usually initiated based on existing compounds. Moreover, Lundbeck's financial predicament pressured the research organization to produce new results faster, which did not fit the new strategy's long-term orientation or its introduction of more-ambiguous and unpredictable research processes.

\subsubsection{The organizational structure for exploration}

Lundbeck's management developed an organizational structure for exploratory research comprising a core team of executive managers assigned to orchestrate exploratory research, including seeking, conducting, and evaluating collaborations. The core team had four members: the executive head of global research, the head of local research, the head of molecular neurobiology, and a business developer specialized in scouting and contracting. Lundbeck designed the structure to allow optimal adaptivity and learning in a context of high uncertainty. It introduced few constraints on action regarding rules, routines, and control, but it relied on implicit but extreme centralization given that two of the four members already had executive decision power.

\subsubsection{Balancing mechanisms}

At the organizational level, the structure of a core executive team allowed Lundbeck to use contextual ambidexterity to balance tensions between exploration and exploitation. Since the core team was also responsible for ongoing exploitation in Lundbeck's research organization, the structure allowed Lundbeck to maintain exploratory and exploitative activities simultaneously. At the managerial level, the team balanced tensions from countervailing demands by continuously unbalancing to favor flexibility. They did this by extensively using heuristics-based, simple-rules 
strategies to counterbalance the constant pressure toward efficiency and fast outcomes. The team's recurrent heuristics in town hall meetings, fireside talks, and their own meetings included "focusing on biological mechanisms," "accepting not knowing the outcomes," and seeking "equal scientific collaboration" with partners who allowed Lundbeck to loosely shape exploratory activities and adapt to emerging outcomes (from observations). These heuristics were rules that sustained Lundbeck's process of increasing exploration.

\subsubsection{Phase 2: Conducting exploratory research with multiple partners}

\subsubsection{The context}

During 2006-2008, the core executive team initiated six large exploratory collaborations, each focused on one or several biological mechanisms involved in at least one neuronal disease. They included collaboration with the Mayo Clinic on the proteins lark and tau regarding Alzheimer's disease; with a Danish biotech firm on antibody therapeutics; with Danish researchers on the protein sortilin regarding Alzheimer's disease; with a European consortia within the Innovative Medicines Initiative on novel medication methods for depression and schizophrenia; with international researchers, supported by the Michael J. Fox Foundation, focusing on Parkinson's disease diagnosis; and with Danish researchers and biotech firms studying the role of microRNAs in neuronal diseases. Scientific staff from Lundbeck was assigned to each collaboration.

\subsubsection{The countervailing organizational and interorganizational demands}

Lundbeck's corporate management group (C-suite) increased pressure on the core team to demonstrate results, demanding frequent presentations of progress and a clear business rationale for each collaboration. This pressure challenged the flexibility needed for the exploratory processes. Moreover, research staff pressured the core team to make their processes more transparent in order to integrate outcomes more gradually, a demand that tested the team's ideas of optimal adaptability. In addition, the team faced significant external pressure. Each collaboration included both 
exploratory and exploitative activities that the team had to integrate. These countervailing demands emerged in the team's daily reflections on the requirements for increasing exploration:

We took a calculated risk; we knew that there was a risk associated with believing in these [animal] models, we found the biology we saw attractive ... and we also knew that it would take some years to mature it, but then we also knew that if we took the chance, we would at some point be met with a demand for trying to relate it to the clinic ... would we be able to find something? Of course, we had some ideas of how we could do that, maybe some quick tests or something very early so it wasn't completely that we didn't know if any of it would work... (from interview, divisional director)

\subsubsection{The organizational structure for exploration}

The organizational structure did not change during this phase. Its flexibility meant that it continued to accommodate Lundbeck's strategic engagement in several emerging knowledge domains, while simultaneously ensuring resources and attention from the corporate management group. Nonetheless, the core team constantly adjusted and perfected its actions. The team continually reflected on the structure's implications, concerning their own processes and in the collaborations. They shared these experiences in workshops with key managers and scientific staff.

\subsubsection{Balancing mechanisms}

The team continued to use contextual ambidexterity and heuristics to flexibly solve problems, to balance countervailing demands within the organization. Yet, the heuristics of "focusing on biological mechanisms," "accepting not knowing the outcomes," and "equal scientific collaboration" were supplemented with new transition-oriented heuristics such as reaching a state of "knowing enough" (from observations). The team used this latter heuristic to signal that an exploratory activity was sufficiently mature to move in house. Meanwhile, the core team balanced countervailing external demands by separating emergent knowledge domains, which later informed an extensive reorganization of Lundbeck's research division. Moreover, the core team balanced for multiple environments by organizing these knowledge domains in prefigurative and partial forms. 


\subsubsection{Phase 3: Adapting the organization to exploratory outcomes}

\subsubsection{The context}

During 2008-2010, exploratory activities led Lundbeck to outline potentially important biological mechanisms requiring continued exploration or, in parallel, exploitative activities. The core team defined in-house counter-projects for some collaborations, distinguishing internal and external activities for the same proteins. Lundbeck's internal portfolio gradually reflected the exploratory strategy.

Yet, a significant change in top management simultaneously prompted new priorities. A new CEO with a business background replaced the former CEO, who had a research background and advocated more exploration. The new CEO initiated a new, organization-wide, large-scale strategy process, called "Synapse," referring to the junction between two nerve cells. This strategy imagined future products based on strengthened internal connections among Lundbeck subunits rather than on external collaborations.

\subsubsection{The countervailing organizational demands}

The changing organizational context led to new demands that challenged Lundbeck's process of increasing exploration. The Synapse strategy increased pressure toward exploitation and efficiency, and the CEO's support for exploration gradually diminished. While Lundbeck continued to build long-term innovation platforms, the interpretation of how they would develop slightly changed. This strategic turn coincided with the exploratory strategy; for the core team, these new demands for exploitation entailed reframing the ongoing exploratory activities by emphasizing exploitative alongside long-term opportunities.

\subsubsection{The organizational structure for exploration}

At the end of this phase, Lundbeck discontinued the organizational structure for exploration and dissolved the core team of executives. Most exploratory collaborations continued but were managed by the team members, with less attention to their strategic importance and more focus on deliverables. Simultaneously, the research organization's structure changed completely. The 
company replaced the matrix of functions and indication areas with a structure of biological mechanisms. Consequently, units named for disorders, such as "Alzheimer's disease," were now named after key biological processes, such as "Synaptic transmission."

\subsubsection{Balancing mechanisms}

Contextual ambidexterity and heuristics continued to be Lundbeck's main ways of balancing exploration and exploitation, but the issues that these mechanisms addressed changed. While shifting to more exploration, the core team had worked as a flexible structure, allowing Lundbeck to prioritize exploration. While shifting back, the structure likewise allowed the team to focus on exploitative opportunities and to sustain an exploratory mindset in the research organization, thereby ensuring that biological hypotheses informed future projects.

\section{2. $S T$}

\subsubsection{Phase 1: Developing organizational structures for exploration}

\subsubsection{The context}

ST developed a more-exploratory strategy in response to changing market dynamics and an emerging "More than Moore" trend, which refers to explorations that do not follow the device scaling and cost reduction of Moore's Law. First, ST's management responded to a major shift from the mobile phone to the smartphone market, resulting in a changing competitive landscape (Nokia, Raspberry vs. Apple). Second, faced with the physical limitations of following Moore's Law, the industry sought alternatives, leading ST's management to explore the "More than Moore" trend of adopting diversification to examine new functionalities.

ST's management considered its strategies and structures optimized for Moore's Law to be insufficient for "More than Moore" exploration. Consequently, in 2005, it developed a new strategy that eventually led to a new exploration subunit: Advanced R\&D. The strategy emphasized exploration and radically new ideas; exploring multiple knowledge domains simultaneously through different engagements and new collaborations; and initiating activities to ensure transparency and knowledge flow between new exploratory areas. 


\subsubsection{The countervailing organizational demands}

ST's new strategy entailed not merely developing a new generation of devices but also exploring unknown territories to acquire new capabilities. This shift entailed another challenge: the decisions of business units drove ST's resource allocation for translating projects from the research to the development phases. With increasing uncertainty, the business units tended to wait before investing in new technologies, which slowed the development of innovative solutions.

\subsubsection{The organizational structure for exploration}

To address these countervailing organizational demands, ST established the Advanced R\&D subunit, a dedicated, semi-formal organizational structure for high-risk exploratory activities. The structure was introduced,

to prepare new solutions ahead of time, to demonstrate their feasibility and drive their maturity up to the point at which they can be selected for process integration within the company's internal fabs (from internal company notes).

Including temporary staff, the subunit comprised 15 people. It was designed to avoid overspecialization and to allow exploration of multiple environments. The structure entailed some constraints on members' actions. Their tasks were to report to Technology R\&D, the main R\&D unit, to participate in project reviews, to report progress, and to seek agreement with top management concerning new domains, alliances, and collaborations. The project reviews had no predefined success criteria but involved discussion of progress and opportunities for creating synergies between Advanced R\&D and other Technology R\&D teams.

\subsubsection{Balancing mechanisms}

At the organizational level, the subunit was part of Technology R\&D but had its own location, which allowed ST to balance exploration and exploitation through organizational separation. As a separate subunit, the core team could flexibly engage in exploratory collaboration, but its anchoring in Technology R\&D ensured that Advanced R\&D's exploratory outcomes were continuously absorbed. At the managerial level, the core team sustained its exploration by 
constantly unbalancing to favor flexibility. They relied on flexibility-injecting structures

emphasizing temporary assignments, prototyping, and alliances rather than on establishing activities in house. Specifically, the core team frequently sent their staff to CEA-LETI, a strategic partner, and accommodated researchers from CEA-LETI. Moreover, to allow employees to focus solely on exploration, they relied on temporary three-year assignments of industrial $\mathrm{PhD}$ students at ST.

\subsubsection{Phase 2: Conducting exploratory research with multiple partners}

\subsubsection{The context}

The core team initiated numerous collaborations in multiple domains of interest to ST, such as Bulk Acoustic Wave (BAW), 3D integration, and Image Sensors. For each knowledge domain, the team relied on different collaborative projects, such as industrial $\mathrm{PhDs}$, direct agreements with RTOs, and European or nationally funded projects. ST continually emphasized collaboration with external partners:

The participation in European and national projects together with a large network of external labs brings the complementary expertise \& competencies, enabling new ideas \& innovation (from internal document).

\subsubsection{The countervailing organizational and interorganizational demands}

Advanced R\&D faced both countervailing organizational and interorganizational demands. From the start, the core team had to deliver results and secure internal sponsors to support the transition of exploratory outcomes to development projects and to ensure resources and staff. At the interorganizational level, the team initiated and engaged in numerous collaborations simultaneously. For the 3D integration domain, these collaborations included consortia of scientists and industrial partners, direct collaboration with research partners such as CEA-LETI, and industrial $\mathrm{PhD}$ collaborations with universities such as Grenoble INP and University of Montpellier. All these collaborations entailed projects at different stages of maturity and various contractual obligations.

\subsubsection{The organizational structure for exploration}


The structure of the Advanced R\&D subunit continued to be semi-formal. During the continual seeking of new knowledge domains, the firm adjusted the structure to reflect current priorities. Consequently, the structure's name changed several times, reflecting new focus areas. Yet, the core team remained stable. Throughout the phase, the same team members were involved in all collaboration processes, ranging from selecting objectives and partners to leading the research. This allowed ST to track all advancements across knowledge domains and to manage exploration and appropriation of results over time. The core team functioned as "knowledge architects" who managed tradeoffs between exploration and exploitation while also detecting new knowledge areas.

\subsubsection{Balancing mechanisms}

The team continued to balance countervailing organizational demands through organizational separation and by using flexibility-injecting structures. During this phase, it also enacted simplification cycling by using its experience to develop new structures while continually reducing structure. The team adjusted the structure to fit each exploratory domain. When the team shifted focus from BAW to 3D integration technology, it updated the structure to incorporate this new domain, without adding complexity.

At the interorganizational level, the core team balanced exploration and exploitation through domain separation, distinguishing domains and managing their activities by combining partial and prefigurative forms. For each domain, the team shifted between exploratory and exploitative activities. They searched for new knowledge domains in fields such as 3D integration, fully depleted silicon on insulator (FD-SOI) technologies, BAW, and Image Sensors and combined these with searches within the knowledge domains that the Advanced R\&D team oversaw. In this process, the team focused on balancing for multiple environments.

\subsubsection{Phase 3: Adapting the organization to exploratory outcomes}

\subsubsection{The context}


Advanced R\&D's exploration led to progress in several domains, including bipolar, BAW, FD-SOI, and 3D integration. Some outcomes were translated into other structures and led to new market solutions. Indeed, ST has a rare ability to master multiple technologies for various markets such as automotive, mobile, industrial, and communication equipment. ST's management continued to emphasize innovation and exploring new opportunities. Moreover, the Technology R\&D center's former director was initially appointed deputy CEO, responsible for technology and manufacturing and sales and marketing. Later, he became the new CEO, and, with his research background, he continued to support exploration.

\subsubsection{The countervailing organizational demands}

Despite successful outcomes, like other semiconductor firms the need to continuously explore new solutions drove ST to emphasize long-term collaborations, spurring a constant need to balance exploration and exploitation. The demand to more rapidly translate exploration into exploitation activities drove ST to establish several exploration subunits for emerging technologies, such as photonics, alongside Advanced R\&D.

\subsubsection{The organizational structure for exploration}

Given the increasingly important role of new 3D integration and derivatives solutions, the Advanced R\&D subunit's structure eventually specialized in domain-driven exploration of 3D integration. Adapting the organization to exploratory outcomes occurred gradually. Exploratory outcomes were passed to other ST teams when they were ready to create a standalone product, when a clear fit with the main portfolio or other departments existed, or when the team chose not to pursue a direction. The Advanced $\mathrm{R} \& \mathrm{D}$ team oversaw this organizational adaptation, and the structure continued to ensure exploratory activities in 3D integration and derivatives as well as the management of multiple external collaborations.

\subsubsection{Balancing mechanisms}

During this phase, ST balanced exploration and exploitation through organizational separation, and Advanced R\&D managers ensured flexibility through simplification cycling. The 
other subunits focusing on exploration benefited from the Advanced R\&D team's development of flexible contracts for highly exploratory projects. At the interorganizational level, the team continued to rely on domain separation, and balanced explorative and exploitative activities by combining prefigurative and partial forms.

\subsection{Summary of findings}

First, the firms established and dynamically adjusted organizational structures for exploration over time, allowing them to shift to more-exploratory strategies. Our cases showed substantial differences in the structures that firms adopted and adjusted over time. Lundbeck developed an informal structure of a core team of executive managers that required substantial unbalancing to remain flexible. The structure allowed Lundbeck to shift to more-exploratory strategies rapidly and extensively. ST developed a semi-formal structure of an Advanced R\&D team that allowed ST to adapt to multiple domains simultaneously, ensuring both exploratory flexibility and efficient adaptation of results.

Second, the firms addressed tensions from countervailing organizational and interorganizational demands by deploying different balancing mechanisms at the organizational and managerial levels. While the firms used similar balancing mechanisms for countervailing interorganizational demands, they employed different mechanisms to address organizational demands. To address the conflicting demands of more-exploratory strategies and drifting toward efficiency, Lundbeck used ambidexterity and extensive heuristics to unbalance in favor of flexibility. To address the conflicting demands of more-exploratory strategies and rapid exploitation cycles, ST used organizational separation along with adding and removing structures to adapt to multiple environments. To address the conflicting interorganizational demands of knowledge domains in various maturational stages, both firms employed domain separation by balancing for multiple environments and by combining prefigurative and partial forms.

Third, the firms' choice of organizational structures and balancing mechanisms affected how they adapted to outcomes. Lundbeck's informal structure and contextual ambidexterity 
allowed it to conduct exploratory activities with almost no constraints on action, resulting in a faster shift to exploration but a short-lived adoption of exploratory outcomes. ST's semi-formal structure for exploration and its balancing through organizational separation enabled it to initiate exploration with some constraints on action, leading to a more gradual shift to exploration and continual adaption to outcomes.

Events in the firms' organizational contexts partly elucidate their adaptation processes. CEOs' changing strategic decisions affected the firms' emphases on exploration or exploitation (or on both) and, consequently, the countervailing demands that the firms needed to balance. For example, the new Lundbeck CEO's emphasis on exploitation strengthened the firm's efficiency drift and required the research managers to work harder to ensure flexibility for exploration. However, we found that while the CEO's strategic decisions clearly affected the firm's shift toward exploration, the research managers' design and adjustments in organizational structures for exploration mainly shaped this shift.

Likewise, the firms' industrial settings partially illuminate their different processes of adjusting structures, balancing demands, and adapting to outcomes. Lundbeck's emphasis on flexibility, ambidexterity, and unbalancing allowed the firm to rapidly achieve long-term results that informed internal exploration and exploitation. This finding makes sense in the context of the pharmaceutical industry, in which firms operate with long-term horizons and sustainable innovation platforms. ST's emphasis on long-term, ongoing exploration with external partners, adjusting for different environments, and incorporating results makes sense in the context of the semiconductor industry, which reflects high volatility and rapid exploration cycles and, therefore, also depends on structures that allow continuously balancing for multiple environments. See Table A.3.

\section{Discussion}

\subsection{Process model}

To summarize our contribution, we offer a process model outlining the firms' adjustment of organizational structures to increase exploration. We adopt a recursive style to theorize process 
(Cloutier and Langley, 2020), which reflects processes as ongoing cycles of adaptation and reproduction. Although our model ends with "organizational adaptation of exploratory outcomes," the premise is that the process continues. The model visualizes the dynamic interplay among developing new strategies for exploration, designing organizational structures, conducting exploratory research, and adapting the organization to exploratory outcomes. External influence from changing market dynamics and emerging knowledge domains continuously affects the interplay of these core elements.

The model transcends the specificity of single cases, but it also attempts to integrate the two different processes: a process initiated by informal structures spurring a fast, extensive adaptation and discontinuation of the structure, and a process initiated with semi-formal structures leading to slower, gradual adaptation and a continued structure. Although the firms' balancing mechanisms are not tied to one process but reflect the interplay of the model's core elements, we have used brackets to show where balancing actions occurred.

Figure 1 here.

Our model describes the following processes (numbers below correspond to numbers in the model). In response to changing market dynamics and trends, firms develop more-exploratory strategies (1). These strategies require that firms counterbalance their existing organizational structures, often optimized for exploitation, by establishing dedicated organizational structures for exploration (2). By allowing more flexibility, these structures enable firms to engage in moreexploratory activities, but doing so involves constantly balancing countervailing demands from within the organization and the external environment (3). Firms balance these demands by deploying, combining, and changing both organizational and managerial mechanisms.

Organizational balancing mechanisms entail either separation or ambidexterity, and managerial balancing mechanisms involve unbalancing to favor flexibility or balancing for multiple domains. 
This process of developing and adjusting organizational structures and balancing mechanisms is iterative and dynamic.

Engaging in external collaborations (4) prompts countervailing interorganizational demands from managing multiple environments and knowledge domains at different stages. To balance these demands, firms combine prefigurative and partial forms of organization. Conducting exploratory research leads to exploratory outcomes and organizational adaptation. Depending on the organizational structures, the process of adaptation takes different forms. An informal structure with few constraints on action allows firms to both shift to exploration and adapt to outcomes faster and more extensively, but the structure is not sustainable in the long term (6a). In contrast, a semiformal structure with more constraints on action enables firms to both shift to exploration and adapt to outcomes more gradually, but the structure seems more sustainable in the long term (6b).

\subsection{Theoretical contributions}

We make three main contributions to research policy studies and organizational theory. First, by adopting a process perspective and focusing on the organizational level, we demonstrate the dynamic interplay between firms' adjustments of organizational structures and shifting to moreexploratory research. We thus contribute to research policy studies of how firms organize exploratory research, which have mainly adopted a covariance model to study firms' external collaborations, and we answer the call for process studies from scholars of research policy and organizational theory (Azagra-Caro et al., 2017; Bahemia et al., 2018; Janssen et al., 2015; Järvi et al., 2018; Kunisch et al., 2017). While contributing mainly to research policy studies, we extend organizational theory on exploration and exploitation. By conducting an empirical study of firms' balancing processes, we answer a call to test the "workability and practicality" of a balancing perspective on empirical data (Schreyögg and Sydow, 2010, p. 1259).

Second, by demonstrating how firms deploy, change, and combine balancing mechanisms at the organizational and managerial levels, we contribute to organizational theory regarding exploration and exploitation. Previous research has focused on either organizational or managerial 
mechanisms (Lavie et al., 2010; Eisenhardt et al., 2010), demonstrating mainly “pure modes of balancing" (Lavie et al., 2010, p. 145). By taking a process perspective, we "relate exploration and exploitation at multiple levels of analysis" (p. 143) and show how firms create hybrid balancing mechanisms across the organizational and managerial levels. These hybrids allow firms to respond to challenges that emerge from operations in dynamic environments. We substantiate Eisenhardt et al.'s (2010) notion of “balancing for multiple environments” (Eisenhardt et al., 2010, p. 1267-1268) by drawing on the work of Järvi et al. (2018), to explain how managers balance conflicting interorganizational demands by combining prefigurative and partial organizational forms.

Finally, through our process-oriented approach, we contribute to studies of organizational adaptation by demonstrating how firms' choice of organizational structures affects their process of adapting to exploratory outcomes. With this finding, we contribute to debates on structure, performance, and adaptation (e.g., Davis et al., 2009) by showing the process implications of adopting different structures - implications that to some extent reflect organizational and industrial contexts.

\subsection{Managerial and policy implications}

Our findings have implications for managers in firms that are shifting to more-exploratory strategies. First, our results suggest that managers should continuously evaluate how well their firms' organizational structures support their firms' exploratory activities, and adjust these structures accordingly. Successful adaptation likely requires high levels of managerial reflection on the implications of organizational structures for long-term exploratory outcomes and the need for continuous structural adaptation.

Second, our results indicate that managers should pay close attention to the interplay of different balancing mechanisms. Here, managers should consider that while a specific combination of balancing mechanisms might effectively manage exploration-exploitation tradeoffs in one phase, it might not do so in another phase. Moreover, managers should try to actively coordinate balancing mechanisms across multiple levels to increase the productive interplay of these mechanisms. 
Our findings have implications for policy makers responsible for science, innovation, and industry. Policy makers should help firms in traditional yet key industries to adopt moreexploratory strategies, by developing mechanisms (legal, financial, taxation) that match the uncertain trajectories of exploratory research. Any support should accommodate firms' continuous adaptation of organizational forms and exploratory directions.

\subsection{Limitations and future research directions}

Our findings and contributions reflect limitations and boundary conditions. We have explored the adjustment of organizational structures in two cases that reflect only one type of organization (established research-based firms) and two industries (pharma and semiconductors). We assume that other types of organizations (startups, research organizations) and other industries might demonstrate different organizational structures, balancing mechanisms, and adaptation processes.

We suggest the following future research directions. First, while our results can apply to industries with similar traits, future research should investigate how the interplay between organizational structures and firms' shifts toward exploration unfolds in empirical settings with other types of industries and organizations.

Second, future research should investigate firms' processes of appropriating exploratory outcomes. While our study shows how organizational structures influence organizational adaptation to exploratory outcomes, it does not elucidate how firms appropriate exploratory outcomes in a change context and under great uncertainty. Therefore, a future direction could explore how firms recognize an attractive outcome and integrate results at different stages of maturation.

Finally, future research should explore how firms' interorganizational relationships affect their design of internal organizational structures for exploration. Recent research has explored how firms adapt their portfolios of interorganizational relationships to changing environmental conditions (de Leeuw et al., 2019). Future research should investigate how firms' 
interorganizational relationships influence their internal organizational designs, a direction that could add depth to our model. 


\section{References}

Azagra-Caro, J.M., Barberá-Tomás, D., Edwards-Schachter, M., Tur, E.M., 2017. Dynamic interactions between university-industry knowledge transfer channels: A case study of the most highly cited academic patent. Research Policy 46, 463-474.

Bahemia, H., Sillince, J., Vanhaverbeke, W., 2018. The timing of openness in a radical innovation project, a temporal and loose coupling perspective. Research Policy 47, 2066-2076.

Battilana, J., Dorado, S., 2010. Building sustainable hybrid organizations: The case of commercial microfinance organizations. Academy of Management Journal 53, 1419-1440.

Bishop, K., D’Este, P., Neely, A., 2011. Gaining from interactions with universities: Multiple methods for nurturing absorptive capacity. Research Policy 40, 30-40.

Bremner, R.P., Eisenhardt, K.M., 2019. Experimentation, bottlenecks, and organizational form: Innovation and growth in the nascent drone industry. Working paper, Stanford Technology Ventures Program.

Bresman, H., Zellmer-Bruhn, M., 2013. The structural context of team learning: Effects of organizational and team structure on internal and external learning. Organization Science $24,1120-1139$.

Cassiman, B., Di Guardo, M.C., Valentini, G., 2010. Organizing links with science: Cooperate or contract?: A project-level analysis. Research Policy 39, 882-892.

Clement, J., Puranam, P., 2018. Searching for structure: Formal organization design as a guide to network evolution. Management Science 64, 3879-3895.

Cloutier, C., Langley, A., 2020. What makes a process theoretical contribution? Organization Theory. https://doi.org/10.1177/2631787720902473

Crescenzi, R., Gagliardi, L., 2018. The innovative performance of firms in heterogeneous environments: The interplay between external knowledge and internal absorptive capacities. Research Policy 47, 782-795. 
Cui, V., Ding, W.W., Yanadori, Y., 2019. Exploration versus exploitation in technology firms: The role of compensation structure for R\&D workforce. Research Policy 48, 1534-1549.

Das, T.K., Teng, B.S., 2002. Alliance constellations: A social exchange perspective. Academy of Management Review 27, 445-456.

Dattée, B., Alexy, O., Autio, E., 2018. Maneuvering in poor visibility: How firms play the ecosystem game when uncertainty is high. Academy of Management Journal 61, 466-498.

Davis, J.P., Eisenhardt, K.M., Bingham, C.B., 2009. Optimal structure, market dynamism, and the strategy of simple rules. Administrative Science Quarterly 54, 413-452.

de Leeuw, T., Gilsing, V., Duysters, G., 2019. Greater adaptivity or greater control? Adaptation of IOR portfolios in response to technological change. Research Policy 48, 1586-1600.

Duysters, G., Lavie, D., Sabidussi, A., Stettner, U., 2018. What Drives Exploration? Convergence of Tendencies Among Alliances Partners and Competitors, in: Academy of Management Proceedings. Academy of Management, Briarcliff Manor, NY, pp. 10203.

Eisenhardt, K.M., 1989. Building theories from case study research. Academy of Management Review 14, 532-550.

Eisenhardt, K.M., Furr, N.R., Bingham, C.B., 2010. CROSSROADS-Microfoundations of performance: Balancing efficiency and flexibility in dynamic environments. Organization Science 21, 1263-1273.

Estrada, I., Faems, D., Cruz, N.M., Santana, P.P., 2016. The role of interpartner dissimilarities in industry-university alliances: Insights from a comparative case study. Research Policy 45, 2008-2022.

Faems, D., Janssens, M., Madhok, A., Looy, B.V., 2008. Toward an integrative perspective on alliance governance: Connecting contract design, trust dynamics, and contract application. Academy of Management Journal 51, 1053-1078.

Farjoun, M., 2010. Beyond dualism: Stability and change as a duality. Academy of Management Review 35, 202-225. 
Fernandez, A.S., Chiambaretto, P., 2016. Managing tensions related to information in coopetition. Industrial Marketing Management 53, 66-76.

Gilsing, V., Nooteboom, B., 2006. Exploration and exploitation in innovation systems: The case of pharmaceutical biotechnology. Research policy 35, 1-23.

Gioia, D.A., Price, K.N., Hamilton, A.L., Thomas, J.B., 2010. Forging an identity: An insideroutsider study of processes involved in the formation of organizational identity. Administrative Science Quarterly 55, 1-46.

Glaser, B.G., Strauss, A., 1967. The Discovery of Grounded Theory: Strategies for Qualitative Research. Weidenfeld and Nicholson, London.

Hammersley, M., Atkinson, P., 1998. Ethnographic Research: A Critical Guide. Longman, New York.

Hannah, D.P., Eisenhardt, K.M., 2018. How firms navigate cooperation and competition in nascent ecosystems. Strategic Management Journal 39, 3163-3192.

Hoang, H., Rothaermel, F.T., 2016. How to manage alliances strategically. MIT Sloan Management Review 58, 69.

Janssen, M., Stoopendaal, A.M.V., Putters, K., 2015. Situated novelty: Introducing a process perspective on the study of innovation. Research Policy 44, 1974-1984.

Järvi, K., Almpanopoulou, A., Ritala, P., 2018. Organization of knowledge ecosystems: Prefigurative and partial forms. Research Policy 47, 1523-1537.

Kobarg, S., Stumpf-Wollersheim, J., Welpe, I.M., 2019. More is not always better: Effects of collaboration breadth and depth on radical and incremental innovation performance at the project level. Research Policy 48, 1-10.

Koryak, O., Lockett, A., Hayton, J., Nicolaou, N., Mole, K., 2018. Disentangling the antecedents of ambidexterity: Exploration and exploitation. Research Policy 47, 413-427. 
Krishnan, R., Geyskens, I., Steenkamp, J.B.E.M., 2016. The effectiveness of contractual and trustbased governance in strategic alliances under behavioral and environmental uncertainty. Strategic Management Journal 37, 2521-2542.

Kunisch, S., Bartunek, J.M., Mueller, J., Huy, Q.N., 2017. Time in strategic change research. Academy of Management Annals 11, 1005-1064.

Langley, A., 1999. Strategies for theorizing from process data. Academy of Management Review 24, 691-710.

Langley, A.N.N., Smallman, C., Tsoukas, H., Van de Ven, A.H., 2013. Process studies of change in organization and management: Unveiling temporality, activity, and flow. Academy of Management Journal 56, 1-13.

Laursen, K., Salter, A., 2004. Searching high and low: What types of firms use universities as a source of innovation? Research Policy 33, 1201-1215.

Laursen, K., Salter, A., 2006. Open for innovation: The role of openness in explaining innovation performance among UK manufacturing firms. Strategic Management Journal 27, 131-150.

Lavie, D., Kang, J., Rosenkopf, L., 2011. Balance within and across domains: The performance implications of exploration and exploitation in alliances. Organization Science 22, $1517-$ 1538.

Lavie, D., Rosenkopf, L., 2006. Balancing exploration and exploitation in alliance formation. Academy of Management Journal 49, 797-818.

Lavie, D., Stettner, U., Tushman, M.L., 2010. Exploration and exploitation within and across organizations. The Academy of Management Annals 4, 109-155.

March, J.G., 1991. Exploration and exploitation in organizational learning. Organization Science 2, 71-87.

Pettigrew, A.M., 1990. Longitudinal field research on change: Theory and practice. Organization Science 1, 267-292. 
Posen, H.E., Levinthal, D.A., 2012. Chasing a moving target: Exploitation and exploration in dynamic environments. Management Science 58, 587-601.

Ragin, C.C., 2014. The Comparative Method: Moving Beyond Qualitative and Quantitative Strategies. University of California Press, Oakland, California.

Raveendran, M., 2020. Seeds of change: How current structure shapes the type and timing of reorganizations. Strategic Management Journal 41, 27-54.

Revilla, E., Rodríguez-Prado, B., 2018. Building ambidexterity through creativity mechanisms: Contextual drivers of innovation success. Research Policy 47, 1611-1625.

Rindova, V.P., Kotha, S., 2001. Continuous “morphing”: Competing through dynamic capabilities, form, and function. Academy of Management Journal 44, 1263-1280.

Schreyögg, G., Sydow, J., 2010. Crossroads_-organizing for fluidity? Dilemmas of new organizational forms. Organization Science 21, 1251-1262.

Staber, U., Sydow, J., 2002. Organizational adaptive capacity: A structuration perspective. Journal of Management Inquiry 11, 408-424.

Stettner, U., Lavie, D., 2014. Ambidexterity under scrutiny: Exploration and exploitation via internal organization, alliances, and acquisitions. Strategic Management Journal 35, $1903-$ 1929.

Strauss, A., Corbin, J., 1994. Grounded theory methodology. Handbook of Qualitative Research 17, 273-85.

Tzabbar, D., Aharonson, B.S., Amburgey, T.L., 2013. When does tapping external sources of knowledge result in knowledge integration? Research Policy 42, 481-494.

Van Maanen, J., 2011. Tales of the Field: On Writing Ethnography. University of Chicago Press, Chicago, Illinois.

Wassmer, U., 2010. Alliance portfolios: A review and research agenda. Journal of Management 36, 141-171. 
Yamakawa, Y., Yang, H., Lin, Z.J., 2011. Exploration versus exploitation in alliance portfolio: Performance implications of organizational, strategic, and environmental fit. Research Policy 40, 287-296.

Yin, R.K., 1994. Case Study Research: Design and Method. Sage, London, UK.

Zhang, K., Jia, X., Chen, J., 2019. Talent management under a big data induced revolution: The double-edged sword effects of challenge stressors on creativity. Management Decision 57, 2010-2031. 
Table 1. Integrative conceptual framework

\begin{tabular}{|c|c|}
\hline Level of analysis & Organizational (from the perspective of the firm) \\
\hline $\begin{array}{l}\text { Countervailing } \\
\text { organizational and } \\
\text { interorganizational } \\
\text { demands }\end{array}$ & $\begin{array}{l}\text { a. Exploration and exploitation create tensions that need to be } \\
\text { reduced (Lavie et al., 2010) } \\
\text { b. Organizations often drift toward efficiency as they grow and } \\
\text { age (Eisenhardt et al., 2010) } \\
\text { c. Firms engage in emergent knowledge domains in different } \\
\text { stages of maturation (Järvi et al., 2018) } \\
\text { d. Organizations simultaneously face several environments } \\
\text { (Eisenhardt et al., 2010) }\end{array}$ \\
\hline $\begin{array}{l}\text { Organizational-level } \\
\text { balancing mechanisms }\end{array}$ & $\begin{array}{l}\text { Modes of balancing (Lavie et al., 2010): } \\
\text { - Organizational separation } \\
\text { - Temporal separation } \\
\text { - Domain separation } \\
\text { - Contextual ambidexterity } \\
\text { Combining organizational forms for different search purposes } \\
\text { (Järvi et al., 2018): } \\
\text { - Prefigurative forms for searching for new domains } \\
\text { - Partial forms for searching within new domains }\end{array}$ \\
\hline $\begin{array}{l}\text { Managerial-level } \\
\text { balancing mechanisms }\end{array}$ & $\begin{array}{l}\text { Unbalancing to favor flexibility (Eisenhardt et al., 2010): } \\
\text { - Heuristics-based simple-rules strategic processes } \\
\text { - Simplification cycling } \\
\text { - Flexibility-injecting structures } \\
\text { Balancing for multiple environments within a single market or a } \\
\text { single organization (Eisenhardt et al., 2010) }\end{array}$ \\
\hline
\end{tabular}


Table 2. Overview of data collection

\begin{tabular}{|c|c|c|c|}
\hline & $\begin{array}{l}\text { Phase 1 } \\
\text { Exploring the firms' contexts for } \\
\text { developing exploratory strategies }\end{array}$ & $\begin{array}{c}\text { Phase 2 } \\
\text { Investigating the firms' organizational } \\
\text { structures for exploratory research } \\
\end{array}$ & $\begin{array}{l}\text { Phase 3 } \\
\text { Examining the firms' organizational } \\
\text { adaptation of exploratory outcomes }\end{array}$ \\
\hline \multicolumn{4}{|c|}{ Case 1: Lundbeck (2009-2011) } \\
\hline Observations & \multicolumn{3}{|c|}{ Weekly core team meetings; strategy sessions; informal conversation. } \\
\hline Interviews & $\begin{array}{l}24 \text { in total: the executive head of } \\
\text { research (8); the head of research } \\
\text { Denmark (6); the divisional director } \\
\text { for molecular neurobiology ( } 7) \text {; a } \\
\text { business developer (3). }\end{array}$ & $\begin{array}{l}14 \text { in total: US scientists and } \\
\text { managers (7); chief scientists (2); } \\
\text { department managers (2); divisional } \\
\text { directors (2); an IP manager (1). }\end{array}$ & $\begin{array}{l}12 \text { in total: the executive head of } \\
\text { research ( } 3) \text {; the head of research DK } \\
\text { (4); the divisional director for } \\
\text { molecular neurobiology (3); other } \\
\text { managers (2). }\end{array}$ \\
\hline $\begin{array}{l}\text { Archival } \\
\text { material }\end{array}$ & $\begin{array}{l}\text { Strategies; key reports (e.g. PwC } \\
\text { "Pharma 2020" report); meeting } \\
\text { material; presentations; e-mails. }\end{array}$ & $\begin{array}{l}\text { Contracts; project descriptions; } \\
\text { project review material; white papers; } \\
\text { e-mails. }\end{array}$ & $\begin{array}{l}\text { Strategy evaluation material; } \\
\text { workshop material; strategies; } \\
\text { reorganization documents; e-mails. }\end{array}$ \\
\hline \multicolumn{4}{|c|}{ Case 2: ST (2010-2013) } \\
\hline Observations & \multicolumn{3}{|c|}{ Weekly team meetings; monthly project reviews; informal conversation. } \\
\hline Interviews & $\begin{array}{l}28 \text { in total: Advanced R\&D team } \\
\text { (10); Technology R\&D leaders (10); } \\
\text { Business Unit leaders (4); IP manager } \\
\text { (2); Innovation \& External Research } \\
\text { Director (2). }\end{array}$ & $\begin{array}{l}27 \text { in total: Advanced R\&D team } \\
\text { employees, managers and industrial } \\
\text { PhD students) (25); Innovation \& } \\
\text { External Research Director (2). }\end{array}$ & $\begin{array}{l}23 \text { in total: Advanced R\&D team } \\
\text { members (10); Business Unit } \\
\text { managers (7); former industrial } \mathrm{PhD} \\
\text { students (5). }\end{array}$ \\
\hline $\begin{array}{l}\text { Archival } \\
\text { material }\end{array}$ & $\begin{array}{l}\text { Project documentation; presentations; } \\
\text { e-mails; minutes; intranet websites; } \\
\text { communication; announcements. }\end{array}$ & $\begin{array}{l}\text { Project documentation; annual results, } \\
\text { updates; presentations; descriptions; } \\
\text { proposals; awards; agreements. }\end{array}$ & $\begin{array}{l}\text { Case documentation; project } \\
\text { descriptions; reports and agreements; } \\
\text { e-mails. }\end{array}$ \\
\hline
\end{tabular}


Figure 1. Process model of the dynamic interplay between adjusting organizational structure and shifting toward exploration

Balancing mechanisms:

- Contextual

ambidexterity;

heuristics-based

simple-rules strategic

processes (case 1)

- Organizational separation; flexibilityinjecting structures; simplification cycling (case 2)

\section{Changing market dynamics}

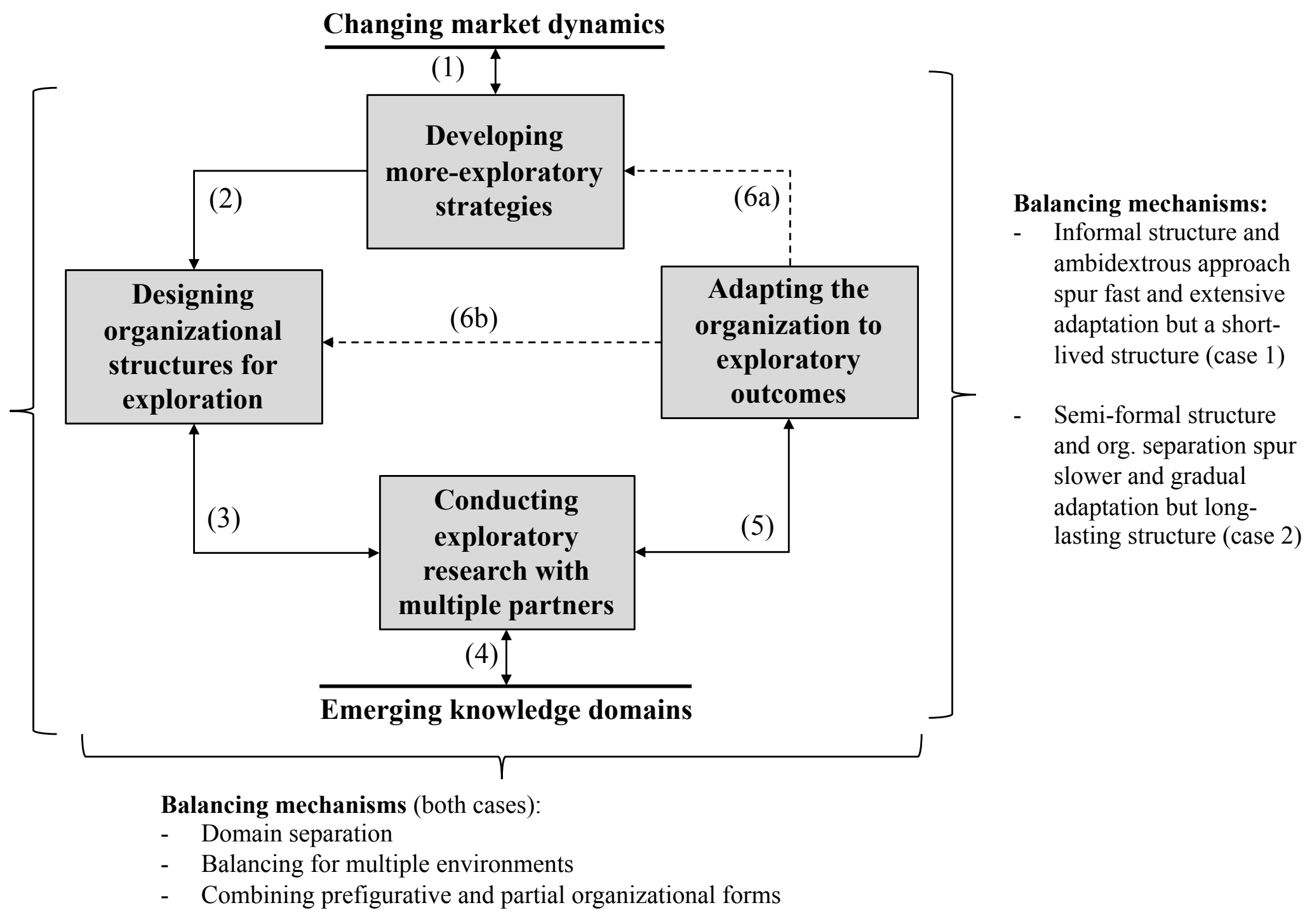


